\title{
URINARY MONOCYTE CHEMOATTRACTANT PROTEIN-1 (MCP-1) IN HIV PATIENTS IN RELATION TO DRUG THERAPY OF HIV AND RENAL FUNCTION
}

\author{
Soheir A. El Lakany ${ }^{(1)}$, DoreenN.Younan ${ }^{(2)}$, Maha A. Ahmad ${ }^{(1)}$ \\ ${ }^{(1)}$ Department of Internal Medicine, ${ }^{(2)}$ Department of Clinical and chemical Pathology, Faculty of Medicine, \\ Alexandria University, Egypt.
}

ABSTRACT:

Introduction: The relationship of the urinary Monocyte Chemoattractant Protein1 (MCP-1)/creatinine ratio to renal affection as manifested by decrease in eGFR and/or microalbuminuria was determined in patients with HIV infection. We compared urinary levels (normalized to urine creatinine) of MCP-1 in HIV infected patients receiving antiretroviral therapy (ART) to those not receiving ART. Fifty one HIV infected subjects were divided into two groups, group 1: not receiving ART, $(\mathrm{N}=20)$, group 2: HIVinfected subjects receiving ART $(\mathrm{N}=31)$. Urinary MCP-1 was also determined in 20 healthy volunteers (group 3). Urinary MCP-1 levels were significantly higher in group 1 and 2 in comparison to group $3(\mathrm{p}$ $=0.001)$. Both urinary MCP-1and urinary $\mathrm{MCP}-1 / \mathrm{Cr}$ ratio were negatively correlated with eGFR in HIV infected patients $(\mathrm{r}=-0.329,-0.347$, and $\mathrm{p}=$ $0.018,0.013$ respectively). CD4+ $\mathrm{T}$ lymphocyte counts were negatively correlated with urinary $\mathrm{MCP}-1(\mathrm{r}=-0.38$ and $\mathrm{p}=0.006)$ while urinary MCP-1/Cr ratio was positively correlated with $\mathrm{uACR}(\mathrm{r}=0.592$, and $\mathrm{p}$ $<0.001$ ). Levels of urinary MCP-1, uACR, urinary MCP-1/Cr. ratio and eGFR did not differ with the use of ART. Urinary ROC test to determine renal dysfunction in HIV infected patients(eGFR $<60 \mathrm{ml} / \mathrm{min}$ ), cutoff value of urinary MCP-1, urinary MCP-1/Cr. ratio and uACR were $(>429 \mathrm{pg} / \mathrm{ml},>$ $1.5(\times 10-6),>456.9 \mathrm{mg} / \mathrm{g} \mathrm{Cr}$ respectively) with sensitivity of $(100 \%, 100 \%$, $83.33 \%$ respectively)and specificity of $(84.62 \%, 100 \%, 93.33 \%$ respectively) with a $\mathrm{p}$ value of $(<0.001,<0.001,=0.001$ respectively $)$.

Conclusion: urinary $\mathrm{MCP}-1 / \mathrm{Cr}$. ratio is sensitive and specific detector of renal affection and correlated to $\mathrm{UACR}$ in patients with HIV infection. Urinary MCP-1 did not differ in patients with HIV with the use of ART.

\section{INTRODUCTION}

$\mathrm{HIV}$ is a member of the group of viruses known as retroviruses, which share a unique life cycle. Once HIV binds to a host cell, the viral envelope fuses with the cell membrane, and the virus's RNA and enzymes enter the cytoplasm. ${ }^{(1)}$ HIV infection diagnosis in adults is based on positive HIV antibody testing and confirmed by a second HIV antibody test relying on different antigens or different operating characteristics and/or positive virological test for HIV or its components confirmed by a second virological test obtained from a separate determination.. ${ }^{(2)}$ HIV infection can generally be classified into four distinct stages: primary infection, clinically asymptomatic stage, symptomatic HIV infection, and progression from HIV infection to AIDS. ${ }^{(3)}$

HIVis transmitted principally in three ways: by sexual contact, by blood (through transfusion of blood products, or contaminated needles), or by passage from mother to child; transmission occurs in utero, as well as during birth. Breast milk from infected mothers has been shown to contain high levels of the virus also. ${ }^{(4)}$

Treating viruses is always difficult because viruses use the translational machinery of the host cell. Most drugs that target the virus also damage the host cell. ${ }^{(5)}$

Drugs that can inhibit enzymes specific to the virus are, therefore, less likely to cause side effects in the host. Most common anti-HIV drugs block key steps in viral reproduction and uptake. Antiretroviral treatment (ART) is initiated if CD4 cell count $\leq 500$ cells $/ \mu 1$ using simplified, less toxic and more convenient regimens as fixed-dose combinations are recommended for first-line ART. Once-daily regimens comprising a non-thymidine nucleoside reverse transcriptase inhibitors (NRTIs) backbone (tenofovirdisoproxil fumarate (TDF) + emtricitabine (FTC) or tenofovirdisoproxil fumarate (TDF) +lamivudine (3TC)) and one nonnucleoside reverse transcriptase inhibitors (NNRTIs) (efavirenz (EFV)) are maintained as the preferred choices in adults, adolescents and 
children older than three years. ${ }^{(6)} \mathrm{HIV}$ infection can cause acute kidney injury (AKI) or chronic kidney disease (CKD). Causes of CKD include HIV-associated nephropathy (HIVAN), HIV-associated glomerulonephritis, thrombotic microangiopathy, malignant hypertension, and amyloidosis. ${ }^{(7)}$

Drug nephrotoxicity can cause AKI or acute on top of CKD. Some of HIV drugs are potentially nephrotoxic as ritonavir (a protease inhibitor) and tenofovir disoproxil fumarate (TDF). ${ }^{(8)}$

The monocyte chemoattractant protein-1 (MCP-1/CCL2) is a member of the $\mathrm{C}-\mathrm{C}$ chemokine family that is a potent chemotactic factor for monocytes. There is, however, evidence that MCP-1 also plays a role in the progression of glomerular lesions, since glomerular expression of MCP-1 correlates with the degree of renal damage in inflammatory and non-inflammatory models of glomerular injury. Furthermore, in humans with crescentic glomerulonephritis, MCP-1 is not only expressed in tubular epithelial cells and leukocytes infiltrating the tubulointerstitium, but also in crescents and parietal epithelium. ${ }^{(9)}$

A consistent increase of urinary $\mathrm{MCP}-1$ concentration is found in patients with a diseased kidney, and this correlates with the degree of urinary albumin /protein excretion and renal damage. In addition to mesangial cells, endothelial cells and infiltrating mononuclear cells, tubularepithelial cells seem to be the major source of MCP-1 in urine. Urinary biomarkers can provide an adjunct to traditional renal biomarkers to assess disease such as glomerular or tubular damage. Increased urinary albumin and MCP1 excretion are detected earlier than altered glomerular filtration rate and azotemia in patients and microalbuminuria is associated with disease progression. Both are mediators of progressive renal damage. ${ }^{(10)}$

\section{AIM OF THE WORK}

Study the relation of the urinary monocyte chemoattractant protein1 (MCP-1)/creatinine ratio to renal affection manifested by decreased eGFR and/or microalbuminuria in patients with HIV infection.

The impact of receiving drug therapy for HIV on renal affection and urinary monocyte chemoattractant protein -1 /creatinine ratio has also been evaluated.

\section{SUBJECTS AND METHODS}

Fifty one patients (51) were studied and divided into 2 groups: group one: 20 patients who have no previous antiretroviral therapy (ART) whether fulfilling or not the WHO criteria for treatment, Group two: 31 patients who receiving ART ((tenofovirdisoproxil fumarate(TDF) +lamivudine $(3 \mathrm{TC})+($ efavirenz(EFV)) and group 3: included 20 age and sex matched healthy controls. Exclusion Criteria:1)Active liver disease (demonstrated by increase transaminases more than double the normal value and/or prolonged prothrombin time and/or evidence of liver cirrhosis by ultrasound),2)Previous history of autoimmune disease e.g. systemic lupus erythematosis (SLE).

HIV patients were recruited from Alexandria Fever Hospital during year 2015and diagnosis of HIV was based on IgG positive serology ( $>0.193$ ) by ELISA confirmed by western blot test. All patients subjected to full history taking including the duration of the disease, the symptoms of HIV, (diaharria, fever and weight loss) and whether there was renal involvement and duration of receiving treatment. Full clinical examination and laboratory investigations including: a- Complete blood count, CD4+T lymphocyte counts. ${ }^{(11)}$ b- Kidney function tests including urea and creatinine, urine analysis, urine albumin/creat. ratio ${ }^{(12)}$, and eGFR (using the CockcroftGault formula) where eGFR is expressed in milliliters per minute. ${ }^{(13)}$

eGFR $=\frac{(140-\text { Age by years }) \times M a s s(i n k i l o g a m s) \times[0.85 \text { if female }]}{72 \times \text { Serum Creatinine (in mg/dL) }}$

c- All controls were only evaluated for renal functions, estimated glomerular filtration rate and MCP-1 levels in urine. Principle of the ELISA test used to detect urinary MCP-1 (Quantikine ELISA, Human CCL2/MCP1Immunoassay, cat. \# DCP00, R\&D systems, USA). ${ }^{(14)}$. Urine samples collected aseptically, mid-stream first urine of the day sample voided directly into a sterile container. Centrifugation done to remove particulate matter then samples stored below $20^{\circ} \mathrm{C}$ until the assay was done. A monoclonal antibody specific for $\mathrm{MCP}-1$ has been precoated onto a microplate. Standards and samples were pipetted into the wells and any MCP-1 present was bounded by the immobilized antibody. After washing away any unbound substances, an enzyme-linked polyclonal antibody specific for MCP-1 was added to the wells. Following a wash to remove any unbound antibody-enzyme reagent, a substrate solution added to the wells and color developed in proportion to the amount of MCP-1 bound in the initial step. The color development was stopped and the intensity of the color was measured.

Urinary MCP-1 corrected to urinary creatinine levels were estimated in all study cases.

\section{STATISTICAL ANALYSIS}

Spearman test was used to test for correlation between MCP-1 and between different parameters and urinary $\mathrm{MCP}-1 / \mathrm{Cr}$. ratio with eGFR and uACR. For abnormally quantitative variables, Mann Whitney test was used to compare between two studied groups and Kruskal Wallis test was used to compare between more than two studied groups. ROC curve analysis was used identify diagnostic accuracy of urinary $\mathrm{MCP}-1$, urinary $\mathrm{MCP}-1 / \mathrm{Cr}$. ratio and 
UACR in the diagnosis of chronic kidney disease. The cutoff point best used for discrimination between diagnostic groups was identified for each, along with its sensitivity, specificity predictive values.

In all statistical tests used, $\mathrm{p}$ value $<0.05$ was considered significant.

\section{RESULTS}

The characteristics of each group are shown in Table 1. Distribution of the studied cases according to mode of HIV infection shown in figure 1, According to our study, mode of HIV infection in most of the cases was unidentified $(35.3 \%)$, secondly HIV was transmitted from husband $(27.5 \%)$, and transmission through IV drug addiction came third by $(25.5 \%)$.The median of duration since HIV diagnosis was higher and the median of CD4 $+\mathrm{T}$ lymphocyte counts was lower in group 2 compared to group 1,with no statistically significant difference ( $p$ value $=0.792$ ). The median of treatment duration in group 2 was 12 months. $15 \%$ of group1 had eGFR $<60 \mathrm{ml} / \mathrm{min}$, and $9.6 \%$ of group 2 had eGFR $<60 \mathrm{ml} / \mathrm{min}$. Although in group $1,25 \%$ had an eGFR $<90 \mathrm{ml} / \mathrm{min}, 22.6 \%$ had an eGFR $<90 \mathrm{ml} / \mathrm{minin}$ group 2.The frequencies of participants with uACR $>0.03 \mathrm{mg} / \mathrm{g} \mathrm{Cr}$, which are considered abnormal pathological levels, with similar rates found in group 1 and group 2,but with no cases in group 3. The level of urinary MCP-1 was not different in group 1 and 2 but statistically significant lower in group 3 . Urinary $\mathrm{MCP}-1 / \mathrm{Cr}$. ratio was not different in between group 1 and 2.

In table 2, we compare the relation of eGFR with urinary $\mathrm{MCP}-1$ and urinary $\mathrm{MCP}-1 / \mathrm{Cr}$. ratio. Both were statistically significant higher in eGFR $<60 \mathrm{ml} / \mathrm{min}$. (p value are $<0.001,<0.001$ respectively)

Correlation between MCP-1 and different parameters: The correlations between MCP-1 and different parameters have been shown in table 3 . Statistically significant negative correlations were found between urinary MCP-1 and each of CD4+ T lymphocyte counts and eGFR. ( $\mathrm{r}=-$ $0.329,-0.38$ respectively and $\mathrm{p}=0.018,0.006$ respectively). There were no significant correlations between urinary MCP-1with $\mathrm{uACR}$ and treatment duration.

\section{Correlation between urinary MCP-1/Cr. ratio with eGFR and uACR:}

Table 4 showed that there was a statistically significant positive correlation between urinary $\mathrm{MCP}-1 / \mathrm{Cr}$. ratio and uACR, $(\mathrm{r}=0.592$, and $\mathrm{p}<0.001)$ and statistically significant negative correlations between urinary MCP$1 /$ Cr. ratio and eGFR. $(r=-0.347$, and $\mathrm{p}=0.013)$.

\section{ROC Curve:}

ROC test has shown that cutoff value of urinary MCP-1, urinary MCP $-1 / \mathrm{Cr}$. ratio and $\mathrm{uACR}$ are $(>429 \mathrm{pg} / \mathrm{ml}$, > $1517.89 \mathrm{pg} / \mathrm{mg}$, and $>456.9 \mathrm{mg} / \mathrm{g} \mathrm{Cr}$ respectively)and sensitivity are $(100 \%, 100 \%$, and $83.33 \%$ respectively)and specificity are $(84.62 \%, 100 \%$, and $93.33 \%$ respectively) with a $\mathrm{p}$ value of $(<0.001,<0.001$, and $=0.001$ respectively) in diagnosing $\mathrm{CKD}$, ( defined as eGFR $<60$ $\mathrm{ml} / \mathrm{min} / 1.73 \mathrm{~m}^{2}$ for $\geq 3$ months \pm kidney damage). There were 6 natients with CKN

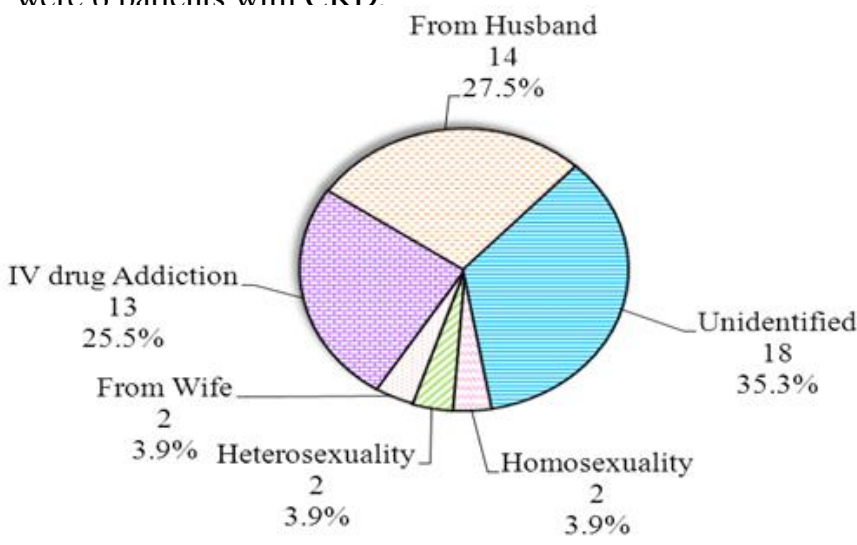

Figure (1):Distribution of the studied cases according to mode of HIV infection

Table (1):Comparison between the different studied groups according

\begin{tabular}{|c|c|c|c|c|}
\hline & $\begin{array}{c}\text { Group 1 } \\
(\mathbf{n}=\mathbf{2 0})\end{array}$ & $\begin{array}{c}\text { Group } 2 \\
(\mathrm{n}=31)\end{array}$ & $\begin{array}{c}\text { Group 3 } \\
(\mathbf{n}=\mathbf{2 0})\end{array}$ & $\mathbf{p}$ \\
\hline Duration since HIV diagnosis: (Months) & $15(0.75-72)$ & $24(3-132)$ & - & $0.063^{\mathrm{a}}$ \\
\hline CD4 + T lymphocyte counts $\left(\right.$ cells/ mm$\left.^{3}\right)$ & $355.5(5-950)$ & $298(18-1264)$ & & \\
\hline$<250$ & $6(30.0 \%)$ & $12(38.7 \%)$ & - & \\
\hline $250-500$ & $9(45.0 \%)$ & $13(41.9 \%)$ & - & $0.792^{\mathrm{b}}$ \\
\hline$>500$ & $5(25.0 \%)$ & $6(19.4 \%)$ & - & \\
\hline Treatment duration (Months) & - & $12(1.5-120)$ & - & - \\
\hline eGFR $(\mathrm{ml} / \mathrm{min})$ & $119.6 \pm 53.8$ & $122.4 \pm 60.3$ & $132.4 \pm 31.0$ & $0.706^{\mathrm{c}}$ \\
\hline Sig.bet. grps & & $\mathrm{p}_{1}=0.848, \mathrm{p}_{2}=0.435, \mathrm{p}_{3}=0.503$ & & \\
\hline$<60$ & $3(15 \%)$ & $3(9.6 \%)$ & $0(0 \%)$ & \\
\hline$<90$ & $5(25 \%)$ & $7(22.6 \%)$ & $0(0 \%)$ & $0.001^{\mathrm{b}}$ \\
\hline Urinary MCP-1 (pg/mL) & $597.2(64-2415)$ & $292(0-3041)$ & $69.5(10-314)$ & \\
\hline Sig.bet. groups & & $\mathrm{p}_{1}=0.506, \mathrm{p}_{2}<0.001^{*}, \mathrm{p}_{3}=0.001^{*}$ & & \\
\hline U ACR (mg/g Cr) & $57.25(4.3-4363.6)$ & $64.5(12.4-13253)$ & - & 0.832 \\
\hline$<30(\mathrm{mg} / \mathrm{g} \mathrm{Cr})$ & $7(35.0 \%$ & $10(32.3 \%)$ & $20(100.0 \%)$ & $00001^{b}$ \\
\hline$\geq 30(\mathrm{mg} / \mathrm{g} \mathrm{Cr})$ & $13(65.0 \%)$ & $21(67.7 \%)$ & $0(0.0 \%)$ & $<0.001$ \\
\hline Sig.bet. grps & & $\mathrm{p}_{1}=0.839, \mathrm{p}_{2}<0.001^{*}, \mathrm{p}_{3}<0.001^{*}$ & & \\
\hline Urinary MCP-1/Cr. Ratio $\times 10^{-6}$ & $0.38(0.1-21.9)$ & $0.35(0.0-54.4)$ & - & $0.923^{\mathrm{a}}$ \\
\hline
\end{tabular}

Group 1: untreated HIV, Group 2: on treatment of HIV and Group 3: healthy controls
(a): Mann Whitney test applied
(b): Chi-square test applied
(c): Kruskal Wallis test applied 
Table (2): Relation of eGFR (ml/min) with urinary MCP-1 and MCP-1/Cr. ratio in cases

\begin{tabular}{lccc}
\hline & \multicolumn{2}{c}{ eGFR $(\mathbf{m l} / \mathbf{m i n})$} & $\mathbf{p}$ \\
\cline { 2 - 4 } & $\begin{array}{c}<\mathbf{6 0} \text { abnormal } \\
(\mathbf{n = 6}=6\end{array}$ & $\begin{array}{c}>\mathbf{6 0}(\mathbf{n o r m a l}) \\
(\mathbf{n}=\mathbf{4 5})\end{array}$ & \\
\hline Urinary MCP-1 $(\mathbf{p g} / \mathbf{m L})$ & $1994(503-3041)$ & $283(0-1867)$ & $<0.001^{*}$ \\
Urinary MCP-1/Cr ratio $\times \mathbf{1 0}^{-\mathbf{6}}$ & $12.22(2.43-54.42)$ & $0.30(0.0-1.52)$ & $<0.001^{*}$ \\
\hline
\end{tabular}

Qualitative data were described using abnormally distributed data was expressed in median (Min. - Max.) and was compared using Mann Whitney test

Table (3): Correlation between MCP-1 and different parameters in cases

\begin{tabular}{lcc}
\hline & \multicolumn{2}{c}{ Urinary MCP-1 (pg/ml) } \\
\cline { 2 - 3 } & $\mathbf{r}_{\mathrm{s}}$ & $\mathbf{p}$ \\
\hline Treatment duration (months) & 0.176 & 0.351 \\
CD4+T lymphocyte counts $\left(\right.$ cells/ $\left.\mathbf{~ m m}^{\mathbf{3}}\right)$ & $-0.380^{*}$ & 0.006 \\
eGFR (ml/min) & $-0.329^{*}$ & 0.018 \\
UACR (mg/g Cr) & 0.238 & 0.093 \\
\hline
\end{tabular}

$r_{s}:$ Spearman coefficient

*: Statistically significant at $\mathrm{p} \leq 0.05$

Table (4):Correlation between MCP-1/Cr. Ratio with eGFR and UACR

\begin{tabular}{lcc}
\hline & \multicolumn{2}{c}{ MCP-1/Cr. Ratio $\left(\mathbf{1 0}^{-6}\right)$} \\
\cline { 2 - 3 } & $\mathbf{r}_{\mathrm{s}}$ & $\mathbf{p}$ \\
\hline eGFR (ml/min) & $-0.347^{*}$ & 0.013 \\
UACR (mg/g cr) & $0.592^{*}$ & $<0.001$ \\
\hline
\end{tabular}

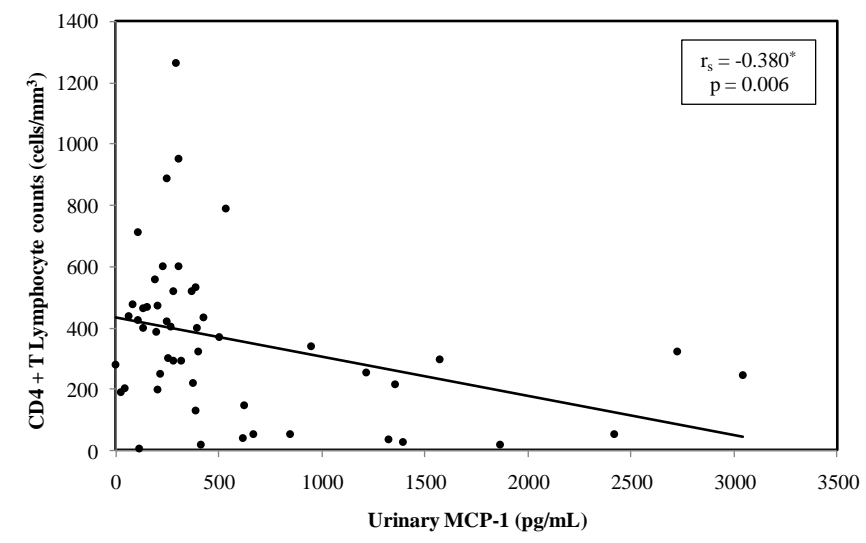

Figure (2):Correlation between MCP-1 with CD4+T lymphocyte counts in HIV patients

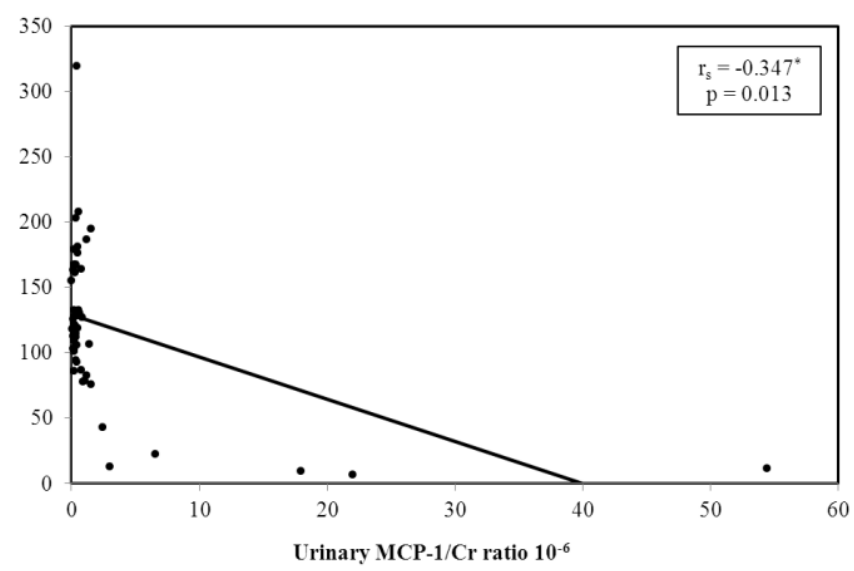

Figure (4):Correlation between urinary $\mathrm{MCP}-1 / \mathrm{Cr}$. ratio and eGFR ( $\mathrm{ml} / \mathrm{min})$

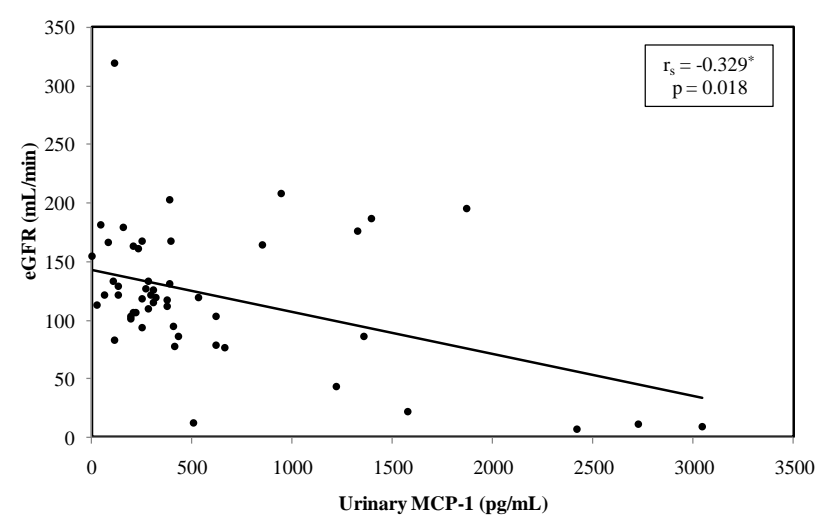

Figure (3): Correlation between MCP-1 with eGFR (ml/min) in HIV patients

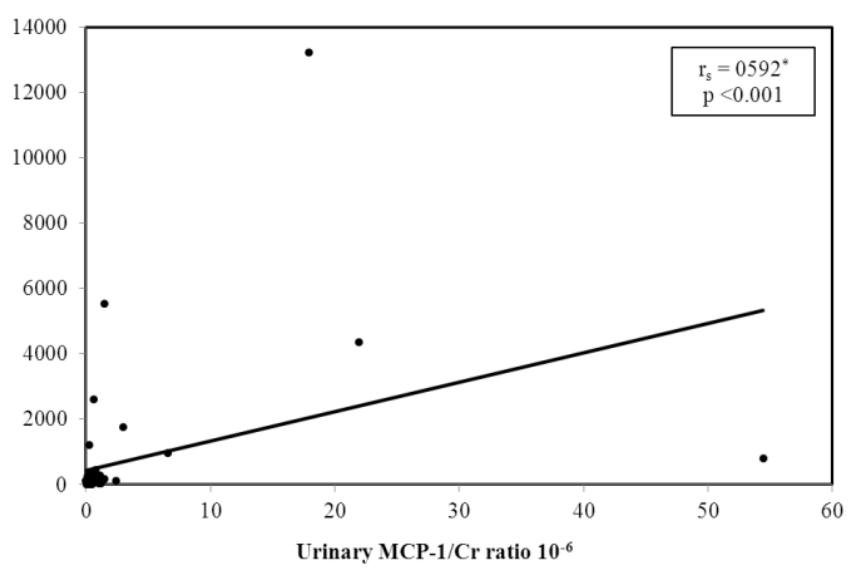

Figure (5): Correlation between urinary $\mathrm{MCP}-1 / \mathrm{Cr}$. ratio and urinary albumin/Cr. ratio $(\mathrm{mg} / \mathrm{g} \mathrm{Cr}$.) 
Table (5): Diagnostic characteristics (sensitivity, specificity and accuracy) for urinary MCP-1, urinary MCP-1/Cr. ratio and u ACR in diagnosing CKD

\begin{tabular}{lcccccccc}
\hline & & & & & & & \\
\hline $\mathbf{U ~ M C P - 1}(\mathbf{p g} / \mathbf{m L})$ & $>429$ & $0.944^{*}$ & $<0.001^{*}$ & 100 & 84.62 & 37.5 & 100 \\
\hline $\mathbf{U ~ M C P - 1 / C r ~ r a t i o ~} \times \mathbf{1 0}^{-\mathbf{6}}$ & $>1.5$ & 1.000 & $<0.001^{*}$ & 100 & 100 & 100 & 100 \\
\hline $\mathbf{U ~ A C R}(\mathbf{m g} / \mathbf{g} \mathbf{~ c r})$ & $>456.9$ & $0.926^{*}$ & $0.001^{*}$ & 83.33 & 93.33 & 62.5 & 97.7 \\
\hline
\end{tabular}

AUC: area under the curve

PPV: positive predictive value

NPV: negative predictive value

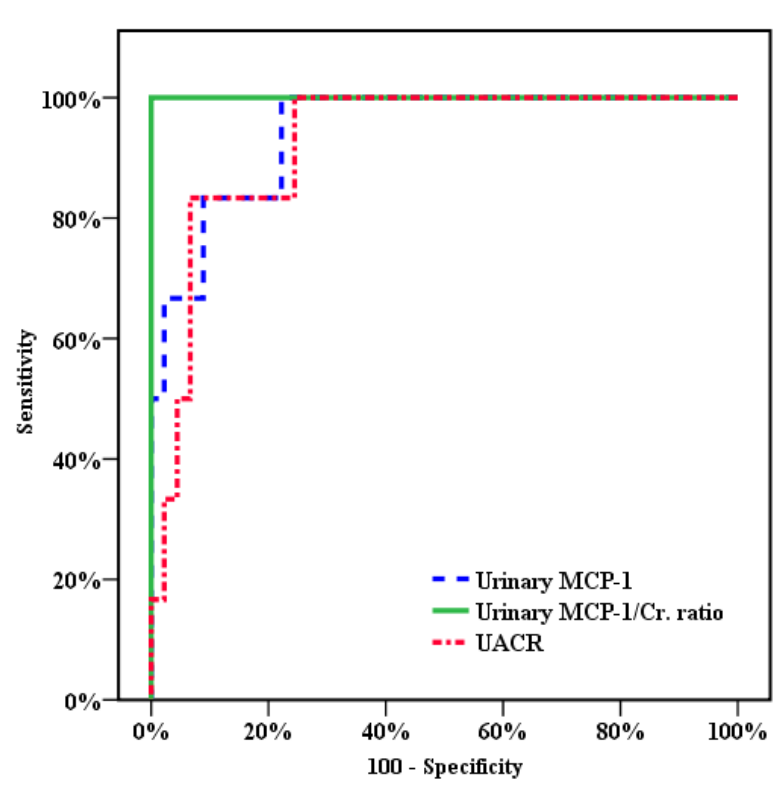

Figure (6): ROC curve for urinary MCP-1, urinary MCP-1/Cr. ratio and $\mathrm{UACR}$

\section{DISCUSSION}

According to the UNAIDS annual global gap report ${ }^{(15)}$ based on national data, the number of people over fifteen years of age living with HIV in 2014 was 7,200 with a range of 4,400 to 12,000 . Renal disease is more common as the HIV infected subjects live longer due to antiretroviral therapy (ART). HIV infection can cause acute kidney injury (AKI) or chronic kidney disease (CKD). Causes of CKD include HIV-associated nephropathy (HIVAN), HIV-associated glomerulonephritis, thrombotic microangiopathy, malignant hypertension, and amyloidosis. ${ }^{(7)}$ Other causes that could be associated with HIV infection are glomerular diseases associated with hypertension and diabetes, HCV co infection and various tubular disorders including tubular toxicity. Clinical implications of finding of microalbuminuria in this population are there for unknown, as several diseases process may contribute to its occurrence in this setting. (6-17) In addition, systemic endothelial dysfunction occurring as part of metabolic syndrome related disorders is also associated with microalbuminuria ${ }^{(18)}$. Abnormalities in metabolism and body composition including visceral adiposity, loss of subcutaneous fat, dyslipidemia and insulin resistance are frequent during ART in HIV infected patients. ${ }^{(19)}$ In this study $67 \%$ of the patients have urinary ACR $\geq 0.03 \mathrm{~g} / \mathrm{g} \mathrm{cr}$ (urinary ACR $0.03-0.3 \mathrm{~g} / \mathrm{g}$ cr in $45 \%$ and $>0.3 \mathrm{~g} / \mathrm{g}$ cr in $21 \%$ ) with a single aseptic morning urine sample. Transient causes of physiologic albuminuria (e.g. exercise) and other inflammatory conditions were excluded in this study e.g. cancer, collagen disorders, and diabetes mellites. Four studies presented data from a single time test and reported microalbuminuria in HIV infected patients ranged 11-20\% while three studies reported microalbuminuria in 2-3 samples of $4-16 \%$. $^{(20-25)}$

Hadigan C, et al, ${ }^{(16)}$ reported prevalence of a single urinary ACR in microalbuminuria range $(17-250 \mathrm{mg} / \mathrm{g}$ for males, $25-355 \mathrm{mg} / \mathrm{g}$ for females) of $17.6 \%$ in HIV infected patients. Microalbuminuria in Hadigan C, et al, was defined as geometric mean ACR of urine sample was found in $14 \%$ in HIV infected patients. Shenia T, et al ${ }^{(26)}$ reported a $12 \%$ prevalance of microalbuminuria ACR $>0.03 \mathrm{~g} / \mathrm{g}$ in single morning spot urine test. A higher prevalence of microalbuminuria in the present study may be due to hypertension or other viral infections affecting kidney as HCV or due to a different exclusion criteria.

Waldman M, et al, ${ }^{(17)}$ approximate those HIV-infected individuals who also were co- infected with $\mathrm{HCV}$ as one third of HIV-infected individuals worldwide, with higher rates of co-infection $(75 \%)$ in HIV patients who were infected parenterally.

In the present study, $20 \%$ of HIV-infected patients were co-infection with $\mathrm{HCV}$ and $25 \%$ of them were IV drug addicts.

In the present study, ACR $>30 \mathrm{mg} / \mathrm{g}$ cr or eGFR $<60$ $\mathrm{ml} / \mathrm{min}$ in HIV-infected patients were not differ by use of ART.

Hadigan C, et al found that ritonavir (a protease inhibitor drug used HIV treatment) associated with micro(16) 
Overton ET, et al (24) found that ritonavir was also associated with renal dysfunction defined as eGFR $<90$ $\mathrm{ml} / \mathrm{min} / 1.73 \mathrm{~m}^{2}$, while Ando M, et al, ${ }^{(25)}$ found that use of a protease inhibitor (ritonavir) in combination with tenofovir (nucleoside reverse transcriptase inhibitors used in treatment of HIV infection) was also a significant risk factor for progression of renal dysfunction (eGFR $<60$ $\mathrm{ml} / \mathrm{min} / 1.73 \mathrm{~m}^{2}$ ) and microalbuminuria.

In our study, ritonavir was not included in ART in HIVinfected patients but tenofovir was used. HIV infected patients have higher urinary MCP-1than healthy non infected controls, with $\mathrm{p}=0.001$. In addition, urinary MCP-1 and urinary MCP-1/cr ratio, both were statistically significant higher in HIV infected patients with eGFR $<60 \mathrm{ml} / \mathrm{min}$ in comparison to those with eGFR > 60 $\mathrm{ml} / \mathrm{min}(\mathrm{P}<0.001,<0.001$ respectively). Urinary MCP-1 and urinary $\mathrm{MCP}-1 / \mathrm{cr}$ ratio were both negatively correlated to eGFR. Higher urinary MCP-1 levels were found to correlate with active inflammation of the kidney in other diseases e.g. systemic lupus erythomatosis (SLE). (27) Sharaf Eldin et al. ${ }^{(27)}$, found that a higher urinary MCP-1 levels were correlated with disease activity in SLE patients and other glomerular diseases e.g. vasculitis. Lloyd CM,et al, ${ }^{(28)}$ found that urinary MCP-1 is associated with active inflammation in the kidney either in glomerular or interstitiam. Kirby NA, et al ${ }^{(29)}$ found that measurement of urinary MCP-1 excretion and urine albumin both normalized to urine creatinine appears to provide a useful means for early, noninvasive detection of kidney disease in mice. Furthermore, urinary MCP1 and microalbuminuria were more sensitive tests for the early detection of kidney disease than serum creatinine.

Shenia T et al, ${ }^{(26)}$ found no correlation between eGFR and urinary MCP-1in HIV-infected patients whether receiving ART or not. Shenia T et al, excluded HIV infected patients who have eGFR $<50 \mathrm{ml} / \mathrm{min} / 1.73 \mathrm{~m}^{2}$ and the percentage of patients co-infected with $\mathrm{HCV}$ was not mentioned. They found that HIV infected patients with lower CD4+ T lymphocyte counts and not receiving ART have higher urinary MCP-1 than healthy non infected individuals.

In the present study, no statistical difference in CD4+ T lymphocyte counts was found in HIV infected patients who receiving ART in comparison to those not receiving $\operatorname{ART}(\mathrm{p}=0.79)$. Also urinary $\mathrm{MCP}-1 / \mathrm{cr}$ ratio did not differ in HIV infected patients who were receiving ART or not. In present study, CD4+ T lymphocyte counts were negatively correlated to urinary $\mathrm{MCP}-1(\mathrm{r}=-0.38, \mathrm{p}=0.006)$ and urinary $\mathrm{MCP}-1 / \mathrm{cr}$ ratio was positively correlated with $\mathrm{UACR}$ in HIV infected patients, this may suggest the role of monocytes and $\mathrm{T}$ lymphocytes infiltration and migration as potential contributors to albuminuria in HIV infection .

MCP-1 is considered a fibrosis marker in HCV liver disease. Whether this applied to renal disease in HIV infected individuals needs further evaluation. (30) Our study is limited in that we did not have histological data as regard monocytes or $\mathrm{T}$ lymphocyte cells infiltrate and degree of renal fibrosis. Biopsy studies were done previously from patients with HIVAN demonstrate a dense infiltrate of monocytes with increased production of MCP-1 ${ }^{(29)}$

\section{CONCLUSION}

Urinary MCP-1, urinary MCP-1/cr ratio or eGFR, did not statistically differ in HIV infected patients treated with ART (tenofovirdisoproxil fumarate(TDF) +lamivudine (3TC)+ (efavirenz(EFV)). Urinary MCP-1 level correlated negatively with eGFR, and CD4+ T lymphocyte counts and urinary $\mathrm{MCP}-1 / \mathrm{cr}$ ratio was positively correlated with uACR, this may suggest the role of monocytes and $\mathrm{T}$ lymphocytes infiltration and migration as potential contributors to albuminuria in HIV infection .

\section{REFERENCES}

1. Muesing MA, Smith DH, Cabradilla CD, Benton CV, Lasky LA, Capon DJ. Nucleic acid structure and expression of the human AIDS/lymphadenopathy retrovirus. Nature 1985;313(6002):450-8.

2. World Health Organization (WHO). WHO case definitions of HIV for surveillance and revised clinical staging and immunological classification of HIV-related disease in adults and children. Geneva: Switzerland: WHO; 2007.

3. World Health Organization (WHO). Interim WHO clinical staging of HIV/AIDS and HIV/AIDS case definitions for surveillance: African region. Geneva: Switzerland: WHO; 2005.

4. Putney J, Oneta M, Mayer K, Seage G, Anderson DJ. Pre-ejaculatory Fluid as potential vector for sexual transmission of HIV-1. Lancet 1992; 340:1470.

5. Passaes CP, Sáez-Cirión A. HIV cure research: advances and prospects. Virology 2014; 454-455:340-52.

6. World Health Organization (WHO). Consolidated guidelines on the use of antiretroviral drugs for treating and preventing HIV infection. Geneva: Switzerland: WHO; 2013.

7. Ross MJ, Klotman PE. Recent progress in HIVassociated nephropathy.J Am Soc Nephrol 2002;13 (12): 2997-3004.

8. Daugas E, Rougier JP,Hill G. HAART-related nephropathies in HIV-infected patients. Kidney Int 2005;67:393.

9. Panzer U, Thaiss F, Zahner G, Barth P, Reszka M, Reinking RR. Monocyte chemoattractant protein-1 and osteopontin differentially regulate monocytes recruitment in experimental glomerulonephritis. Kidney Int 2001; 59:1762-9.

10. Wada T, Yokoyama H, Su SB, Mukaida N, Iwano M, DohiK, et al. Monitoring urinary levels of monocyte chemotactic and activating factor reflects disease activity of lupus nephritis. Kidney Int 1996; 49:761-7.

11. Bofill M, Janossy G, Lee CA, MacDonald-Burns D, Phillips AN, Sabin C, et al. Laboratory control values for CD4 and CD8 T lymphocytes. Implications for HIV-1 diagnosis. Clin Exp Immunol 1992;88(2):243-52.

12. Israni AK, Kasiske BL. Laboratory assessment of kidney disease: glomerular filtration rate, urinalysis, and proteinuria. In: Brenner Rector's The Kidney. $9^{\text {th }}$ ed. Taal MW, Chertow GM, Marsden PA, et al., (eds) Philadelphia Pa: Elsevier Saunders; 2011. chap25;889 
13. Cockcroft DW, Gault MH. Prediction of creatinine clearance from serum creatinine. Nephron 1976; 16 (1): 31-41.

14. Deshmane SL, Kremlev S, Amini S, Sawaya BE. J. Interferon Cytokine Res 2009; 29: 313-26.

15. NPA Egypt. Global AIDS response progress report, Egypt. Egypt: NPA; 2014.

16. Hadigan C, Edwards E, Rosenberg A, Purdy JB, Fleischman E, Howard L. et al Microalbuminuria in HIV Disease Am J Nephrol 2013;37:443-51.

17. Waldman M, Marshall V, Whitby D, Kopp JB. Viruses and Kidney Disease: Beyond HIV, Semin Nephrol 2008; 28:595-607.

18. Szczech LA, Grunfeld C, Scherzer R, Canchola JA, van der Horst C, Sidney S, et al: Microalbuminuria in HIV infection. AIDS 2007; 21: 1003-9.

19. Grinspoon S, A. Cardiovascular risk and body fat abnormalities in HIV-infected adults. N Engl J Med. 2005 Jan 6;352 (1):48-62.

20. Baekken M, Os I, Sandvik L, Oektedalen O. Microalbuminuria associated with indicators of inflammatory activity in an HIV-positive population. Nephrol Dial Transplant 2008; 23:3130-7.

21. Szczech LA, Menezes P, Quinlivan EB, van der Horst C, Bartlett JA, Svetkey LP. Microalbuminuria predicts overt proteinuria among patients with HIV infection. HIV Med 2010; 11:419-26.

22. Wyatt CM, Hoover DR, Shi Q, Tien PC, Karim R, Cohen $\mathrm{MH}$, et al: Pre-existing albuminuria predicts AIDS and non-AIDS mortality in women initiating antiretroviral therapy. Antivir Ther 2011;16:591-6.

23. Yanagisawa N, Ando M, Ajisawa A, Imamura A, Suganuma A, Tsuchiya K, et al: Clinical characteristics of kidney disease in Japanese HIV-infected patients. Nephron Clin Pract 2011;118:c285-91.

24. Overton ET, Patel P, Mondy K, Bush T, Conley L, Rhame F, et al: Cystatin $\mathrm{C}$ and baseline renal function among HIV-infected persons in the SUN Study. AIDS Res Hum Retroviruses 2012;28:148-55.

25. Ando M, Yanagisawa N, Ajisawa A, TsuchiyaK, Nitta K. Urinary albumin excretion within the normal range is an independent risk fornear-term development of kidney disease in HIV-infected patients. Nephrol Dial Transplant 2011; 26: 3923-9.

26. Shinha T, Mi D, Liu Z, Orschell CM, Lederman MM, Gupta SK. Relationships Between Renal Parameters and Serum and Urine Markers of Inflammation in Those With and Without HIV Infection. AIDS Res Hum Retroviruses 2015; 31(4): 375-83.

27. Sharaf Eldin HM, Helal M. Urinary MCP-1 as a Biomarker for Lupus Nephritis Med Cairo Univ 2013; 81(2): 223-8.

28. Lloyd CM, Minto AW, Dorf ME, Proudfoot A, Wells TN, Salant DJ, etal. RANTES and Monocyte Chemoattractant Protein-1(MCP-1) Play an Important Role in the Inflammatory Phase of Crescentic Nephritis, but Only MCP-1 Is Involved in Crescent Formation and Interstitial Fibrosis. J Exp Med 1997; 185(7): 1371-80.

29. Kirby NA, Stepanek AM, Vernet A, Schmidt SM, Schultz CL, Parry NMA, et al. Urinary MCP1 and Microalbumin Increase Prior to Onset of Azotemia in Mice with Polycystic Kidney Disease. Comparative Medicine 2014; 64(2): 99-105.

30. Farci P, Wollenberg K, Diaz G, Engle RE, Lai ME, Klenerman $\mathrm{P}$, et al. Profibrogenic chemokines and viral evolution predict rapid progression of hepatitis $\mathrm{C}$ to cirrhosis. Proc Natl Acad Sci USA 2012; 109:14562-7. 